\title{
Differences of Wound Healing in the Buccal Part and Oral Mucosa Labial After Giving Lemongrass Extracts (Cymbopogon ciratus)
}

\author{
Ameta Primasari ${ }^{1,}$, Edikin Raja Sinulingga ${ }^{2}$ \\ Department of Oral Biology, Faculty of Dentistry, Universitas Sumatera Utara, Medan, Indonesia
}

Email address:

ameta.primasari@usu.ac.id (A. Primasari)

*Corresponding author

\section{To cite this article:}

Ameta Primasari, Edikin Raja Sinulingga. Differences of Wound Healing in the Buccal Part and Oral Mucosa Labial After Giving Lemongrass Extracts (Cymbopogon ciratus). International Journal of Homeopathy \& Natural Medicines. Vol. 5, No. 1, 2019 , pp. 36-41. doi: $10.11648 /$ j.ijhnm.20190501.16

Received: February 3, 2019; Accepted: May 27, 2019; Published: June 20, 2019

\begin{abstract}
Lemongrass is one of the plants that widely used as traditional medicine in Indonesia. Lemongrass contains bioactive substances such as flavonoids, phenolic acids and tannins which act as anti-inflammatory and antioxidants that influence the wound healing process. The aim of this study was to compare the differences in buccal and labial mucosal wound healing, and to see the effect of lemongrass extract on the process of increasing oral mucosal epithelial thickness in white rats. This research is a pure experimental design with a post test-only design with control design. This study used 21 white rats divided into 3 groups where the first group of 100\% lemongrass extract, the second group of 50\% lemongrass extract, and the third group as the treatment that was not treated. The results of the One-way ANOVA and Post-hoc LSD test on the buccal mucosa showed significant differences with the labial mucosa. There were no significant differences in the buccal section with the second group and the third group $p=0.74(p<0.05)$. There were no significant differences in the labial section with the first and second groups, but there were significant differences with the third group $p=0.003$ ( $p<0.05$ ). The effect of lemongrass extract has effectiveness in accelerating healing of oral mucosal wounds in white rats. There was also an increase in the thickness of the oral mucosal epithelium after administration of lemongrass extract with concentrations of $100 \%$ and $50 \%$. Based on the research that has been done it can be concluded that healing wounds of the buccal mucosa heal faster than labial mucosal wounds because the buccal part contains saliva which has an important role in the wound healing process.
\end{abstract}

Keywords: Lemongrass Extract, Wound Healing, Wound Length, Thickness of the Epithelium, Oral Mucosa, White Mice

\section{Introduction}

Lemongrass has active substances such as alkaloids, flavonoids, saponins, tannins, pheonolic acid, and terpenoids. In the dried lemongrass, its content is the most abundant phenolic acid, flavonoids and tannins that act as antioxidants that are useful in the treatment of wound [1]. Flavonoids, pheonolic acid and tannins in lemongrass has antimicrobial and antibacterial substances that work as antioxidants to inhibit spending free radicals such as cyclooxygenase (COX), lipooxygenase, and inducible Nitric Oxide Synthase (iNOS) and changing the intracellular pathways in cells imun [2].

The oral mucosa contains two layers namely the epithelium and connective tissue (lamina propria) [3]. The oral epithelium is the outermost layer of the mucosa that functions as a protection for the underlying layer. While the lamina propria is a layer of fibers that are mutually bound and function to provide strength to the epithelial layer Epithelial cells are the cells keratinocytes largely different from the lamina propria is a loose connective tissue formed under the epithelium consisting of fibroblast cells, lymphocytes, macrophages, eosinophilic leukocytes, mast cells and plasma cells, small blood vessels and glands. Epithelial cells undergo a process of maturation, when the cells are mature will be pushed towards the surface. Regeneration of the epithelium derived from mitosis occurs in the epithelial cells are pushed to the top layer which ultimately do not have a cell nucleus and increasingly thinner [4-5]. 
The process of mitosis in epithelial cells occur continuously. The number of cells lost in the superficial layer is generally balanced by the number of new cells from the basal cell mitosis results. Epithelial cells experience regeneration every 14-21 days starting from the cuboidal basal cell, mating upwards over more polygonal forms, namely spinosum cells, lifted up more flat, and granules and the core disappears into dead cells without nuclei called horn cells. Horn cells continuously escape the surface of the skin called desquamation [5].

Oral mucous wounds are the loss or damage of some mucosal tissue caused by physical or chemical actions [6]. Wounds will trigger a healing reaction that is the body's mechanism to restore damaged tissue integrity. At least there are 3 phases in wound healing, namely in the inflammatory phase, vasoconstriction and formation of blood clots occur. When bleeding stops, platelets release cytokines to attract inflammatory cells and release vasoactive substances to increase vascular permeability. In the proliferative phase, granulation tissue is formed and the tensile strength of the wound is increased. Then a remodeling phase occurs that reshapes new tissue. Wounds are said to heal if the surface can reunite, the tissue strength that reaches normal is obtained, does not interfere with its normal function, and all signs of inflammation have disappeared [7].

Saliva has an important role in the biological processes that occur in the oral cavity as a lubricant in mastication, ingestion of food, cleaning and protection from dental caries. Saliva function will run maximally if the saliva flow rate increases. Saliva can be stimulated by mechanical and chemical means. In the mechanical process can be in the form of masticatory activity while in the chemical process in the form of a casting effect such as acid, sweet, salty, and bitter. Saliva contains growth factors such as Epidermal Growth Factor (EGF) which is believed to function as a wound healing factor in the oral cavity so that the wound heals faster than the wound on the skin [8].

According to Hairi $\mathrm{M}$ et al research shows that the results of lemongrass extract with a concentration of $50 \%$ and $100 \%$ in the wound can occur healing in the mucosa. At a concentration of $100 \%$ healing is faster than the concentration of $50 \%$ [9].

This study aims to look at differences in the healing of buccal and labial parts, and to determine the role of lemongrass in increasing epithelial thickness.

\section{Research Methodology}

The type of this research is trulya experimental design with a posttest only design with control design. This study uses 21 white mice divided into 3 groups, namely $100 \%$ lemongrass extract group, 50\% lemongrass extract group, and control group (not treated).

Lemongrass extract is carried out at Universitas Sumatera Utara (USU) Pharmaceutical Phytochemical Laboratory. Identification and sample testis carried out in the Perumahan Tikus Sunggal and identification of epithelial thickness test is carried out in Anatomical Pathology of Medical Faculty of
USU. To calculate the sample size in this study is using the Federer formula.

The result data is processed computerically. The analysis used in this study is to use the Saphiro-Wilk test because it is more effective and valid to use for small numbers of samples and using the homogeneity test using Levene's test because it is used to test the similarity of variance from several populations. Statistical significance is obtained if the value is p $<0.05$. Followed by Post-Hoc LSD (Least Significance Different) analysis to find out which groups showed significant differences. To see the thickness of the epithelium is only done descriptively.

\subsection{Preparation of Lemongrass Extract}

Before making lemongrass extract, lemongrass is washed first using running water, then cut into small pieces. Then lemongrass is dried at $40^{\circ} \mathrm{C}$ for 48 hours using the oven. The dried lemongrass is soaked with $96 \%$ ethanol to ethanol $1 \mathrm{~cm}$ above the surface of the sample, soaking is done for $3 \times 24$ hours while stirring occasionally, and soaking again for $2 \times 24$ hours. Then evaporated with a vacuum rotary evaporator with a heating temperature of $40-50^{\circ} \mathrm{C}$, until the extract is thick. The ethanolfree test was carried out by weighing the heated extract and the cooled extract, if the weight of the extract was the same then it could be concluded that the extract had been free of ethanol.

\subsection{Making Mucosal Epithelial Preparations}

Incisions are made $1 \mathrm{~cm}$ long and $0.5 \mathrm{~mm}$ deep in the labial section using a sterile scalpel, the blade used is a disposable blade, the blood coming out is cleaned with distilled water. Samples were taken by means of purposive sampling, the epithelium was then put into $10 \%$ formalin. The mucosal epithelium was made by histology preparations stained with Eosin Hemactocillin.

\section{Result}

In this study has showed that wound closure on the part of the buccal mucosa faster than on the labial mucosa, with administration of $100 \%$ concentration lemongrass, the wound was tightly closed on the 6th day while the labial mucosa was tightly closed on day 7 th. While, with $50 \%$ lemongrass administration, the wound of the buccal mucosa was tightly closed on day 7 compared to labial mucosa on day 8th. The results of the One-way ANOVA test on the buccal mucosa showed significant differences with the labial mucosa ( $p$ $<0.05)$.

Data collected then tabulated, the test using the ShapiroWilk normality and homogeneity test using Levene's test. Sapjiro-Wilk test results for all groups showed a value of $\mathrm{p}>$ 0.05 , which means that the data distribution is normal. Then the data is tested homogeneity of variance using Levene's test and the results obtained with $\mathrm{p}=0.277(\mathrm{p}>0.05)$, which means a homogeneous distribution of the data. The data analysis followed using One-Way ANOVA analysis showed the value of $p=0.016(p<0.05)$, which showed a significant difference 
between treatments that do Post-hoc LSD analysis to determine which group showed a significant difference.

Table 1. Results of Post-Hoc Analysis of Buccal Section.

\begin{tabular}{llll}
\hline & Lemongrass Extract 100\% & Lemongrass Extract 50\% & Control Group \\
\hline Lemongrass Extract $100 \%$ & 0.17 & 0.17 & $0.009^{*}$ \\
Lemongrass Extract $50 \%$ & 0.009 & 0.74 & 0.74 \\
Control Group & & \\
\hline
\end{tabular}

Information:

Green*: There are significant differences $(\mathrm{p}<0.05)$

Red: There is no significant difference $(\mathrm{p}>0.05)$

Table 2. Results of Post-Hoc LSD Analysis of labia Section..

\begin{tabular}{llll}
\hline & Lemongrass extract 100\% & Lemongrass Extract 50\% & Control Group \\
\hline Lemongrass extract $100 \%$ & 0.44 & 0.44 & $0.001^{*}$ \\
Lemongrass Extract $50 \%$ & $0.001 *$ & $0.003 *$ & $0.003^{*}$ \\
Control Group & & \\
\hline
\end{tabular}

Based on Post-hoc analysis of LSD, 100\% lemongrass extract group showed no significant difference with lemongrass extract $50 \%$ group, and the control group. But the acceleration of wound healing seen with the invisibility of the reduced length of the wound.

On the table 1, 50\% lemongrass extract group showed no significant difference with the control group (0.74), so that the buccal does not have a significant influence of healing process. From these results, it appears that the extracts of lemongrass $100 \%$ concentration, the faster the wound healing that may be caused by the active substance content of more extracts with higher concentrations.

Based on Post-hoc analysis of LSD, 100\% lemongrass extract group showed no significant difference with lemongrass extract group $50 \%$, but seen the acceleration of wound healing by images of the reduced length of the wound

In Table 2 shows the lemongrass extract $50 \%$ group there were significant differences with the control group. Table results showed that the healing in the group extracts $100 \%$ faster recovery compared with lemongrass extract 50\%. Visible lemongrass extract concentration to $100 \%$ faster healing of wounds that might be caused by the active substance content of more extracts with higher concentrations.

Results can be observed under the microscope with the state of the buccal mucosa tissue taken from rats then performed HE staining

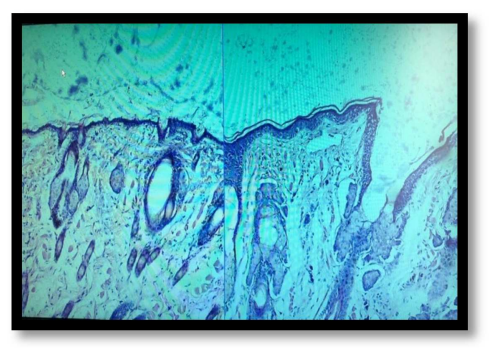

Figure 1. Histological Oral Mucosal Control group (left) and Group Lemongrass Extract Concentrations of 100\% (right) Observation On Day -7 With 100x Magnification (doc).

In the picture above, it looks epithelial tissue in which there is no treatment control compared with lemongrass extract wound by $100 \%$. The epithelial tissue in the control group and the group $100 \%$ composed of connective tissue, epithelial layers and layers of keratin. Discontinuation of epithelial tissue in rats that were given the incision is still visible, but the proliferation of epithelial tissue are seen. Clinically, lemongrass extract group showed a keratin in the top epithelial layer thicker than the control group were not treated. The state of keratin and epithelial layer over the entire surface epithelium concatenated (intact).

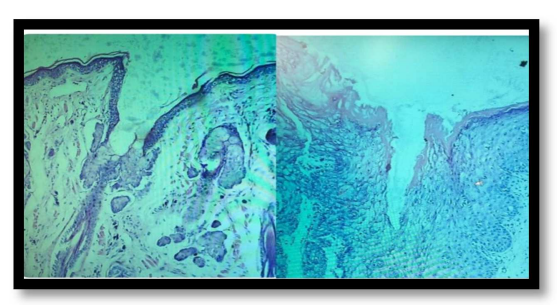

Figure 2. Histological Oral Mucosal Lemongrass Extract Group 100\% (left) After Observation Day- 7 and Group of Lemongrass extract concentration of $50 \%$ (right) After Observation, With 100x Magnification (doc).

In the picture above, it looks epithelial tissue in the group of lemongrass extract $100 \%$ compared with lemongrass extract injuries by $50 \%$. The epithelial tissue in groups of $100 \%$ and $50 \%$ composed of connective tissue, epithelial layers and layers of keratin. Discontinuation of epithelial tissue in rats that were given the incision is still visible, but the proliferation of epithelial tissue are seen. Clinically, lemongrass extract group showed a keratin in the top epithelial layer thicker than the group of $50 \%$ untreated. The state of keratin and epithelial layer over the entire surface epithelium concatenated (intact).

\section{Discussion}

Laboratory experimental studies on extracts of lemongrass (Cymbopogon ciratus) on wound healing in mice oral mucosa is to prove that the extracts of lemongrass has a length of wound healing effect, the role of saliva on wound healing and increase the thickness of the epithelium. This study was also conducted to analyze the effect of extracts of lemongrass on a long healing wound inside (buccal mucosa) 
and the outside (labial mucosa). This study is an experimental research laboratory that uses 21 white male mice whose only objective was to study, not for diagnostic or therapeutic.

According to research on the effects of extracts of lemongrass (Cymbopogon ciratus) to the length of the labial mucosa of mice clinically to determine the effect of lemongrass extract to the length of the labial mucosa wound clinically mice by measuring the length of the wound. The concentration used was $25 \%, 50 \%$, and $100 \%$ indicates that the concentration of $100 \%$ faster recovery than the lower concentration [9]. Same study regarding the effectiveness of the test extracts of lemongrass to healing cuts on white mice with a concentration of $30 \%, 60 \%$, and $80 \%$ indicated that there were no differences effectiveness lemongrass extract $30 \%, 60 \%$, and $80 \%$ compared to the negative control group given only distilled water treatment and positive control [10].

Research conducted on the effectiveness of the test leaf extract kecombrang against cuts in rabbits with a concentration of $5 \%, 7 \%$ and $9 \%$ indicated that the concentration of $9 \%$ more effective for curing the wound healing [11]. Research on the effects of test aloe extract on wound healing prove that aloe vera extract has the effect of speeding up healing of the incision on mice [12]. Ethanol topical noni leaf extract is also very useful in wound healing, but statistically clove extract at a concentration of $20 \%, 40 \%$, and $60 \%$ proves that the concentration of $60 \%$ already affecting the number of capillaries and wound healing in white mice [13-14].

The concentrations used in this study was $100 \%$ and $50 \%$. Selection of concentration and research procedures used in this study is more or less based on the previous studies conducted by Hairi $M$ about the effect of extracts of lemongrass (Cymbopogon ciratus) to the length of the labial mucosa wound mice clinically. This study was also conducted to determine the effect of lemongrass extract to the length of the labial mucosa wound white rat clinically by measuring the length of the wound. In this study showed that the concentration of $100 \%$ heal faster than $50 \%$ of lemongrass extracts. Lemongrass extracts that contain bioactive substances flavonoids, acid and tannins pheonolic more active role than the other concentration [9].

Extracts of lemongrass with a concentration of $100 \%$ and $50 \%$ can accelerate the healing of the incision on the oral mucosa male mice when compared to mice which not given. The treatment as extracts of lemongrass has a content of bioactive substances in lemongrass, such as flavonoids, phenolic acids and tannins that contribute to the phases of wound healing for these substances trigger a variety of inflammatory and immune response that serves as a signaling mechanism for regulation redox [2]. Where antioxidants can also recognize a very minimal oxidative stress that will trigger an important protection mechanism in the improvement of the structure and integrity tissue [15]. There is a polyphenol compound which is a group of chemical substances found in lemongrass has the effect antiinflammatory [16]. Research on lemongrass extract for anti- inflammatory and analgesic evaluates to indicate that the lemongrass is able to reduce inflammation and perifer pain [17]. Research lemongrass extract about new sources and new anti-inflammatory drug showed anti-inflammatory effects through inhibition of proteasome Lemongrass, and cytokines in human macrophages. At the stage of the initial stage of wound healing will happen after homeostatic inflammatory phase, proliferation phase and remodeling phase [16].

Research using saliva on cutaneous wound healing in mice have shown that saliva can accelerate wound healing, so that saliva containing EGF can be a source of new drugs for wound healing. This study proved that saliva also plays an important role in wound healing than wounds that were not affected saliva [18].

Epithelialization is stages of improvement wound repair, the migration of keratinocytes, keratinocyte proliferation and differentiation into stratified epithelium neoepithel layer [19]. Pathophysiology of the acute wound healing where there is a reshaping of the dermis begins on day 3 or 4 after treatment, with the characteristics of the formation of neovascularization and accumulation of fibroblasts. Type III collagen secreted by fibroblasts maximum between days 5 and 7, after which it will change the phenotype of fibroblasts into miofibroblasts. On the day of the 7 th to 9th epithelialization and basement membrane zone (BMZ) has been formed. Epithelialization can be demonstrated by measuring the thickness and width of the epithelial gap formed [20].

The observation day 10 showed that the lemongrass extract can improve epithelialization compared with untreated. Increased epithelialization in the group receiving treatment in the form of epithelial thickness and width of the gap narrowed or thinned. This is consistent with research on banana tree bark extract in the process of wound healing in mice showed perfect epithelialization which one of them characterized by epithelial wound closing gap perfectly. Wound healing is strongly influenced by epithelialization process, the faster the sooner the wound healing [21]. Research on the skin where it is stated in the wound healing or improving perilously close to normal epithelial thickness of about 0.04 to $1.5 \mathrm{~mm}$ [22]. Epithelialization process will restore the epidermis intact as before and the factors involved is the migration and proliferation of keratinocytes, the epidermal differentiation neoepithel become layered [19].

The difference epithelialization in group concentration of $100 \%, 50 \%$ and the control group due to differences concentration lemongrass extracts. Improvement of scar tissue epithelialization possible because lemongrass extract containing pheonolic compounds that affect the wound healing mechanism that the tannins and flavonoids [23]. Flavonoids are important role in improving wound healing. This substance has the effect anti microbial and responsible for wound contraction and increased epithelialization speed [21]. Research on lemongrass extract for wound healing tannins which have active substances that act as antioxidants and antimicrobials, wound contraction and speed increase 
epithelialization [24]. Studies using noni to see wound healing activity stated that the collagen is denser. Formation denser extracellular matrix will spur epithelialization process keratinocytes [25]. Tannin alleged role in the regulation of transcription and translation of vascular endothelial growth factor (VEGF) [26]. VEGF role to epithelialization wound healing act not only on vascular endothelial cells of the skin but also on keratinocyte and the same immune cells to stimulate angiogenesis and restore perfusion oxigen [27].

The study of the effectiveness test of $70 \%$ ethanol extract of Karamunting leaves on re-epithelialization of incisional wounds in wistar mice carried out the process of taking epithelial tissue without being killed [28]. The same study but in the process of taking epithelium by doing punch biopsy (diameter $2.5 \mathrm{~mm}$ ) on the gingival mucosa of mice [29]. This study has limitations in taking epithelial tissue, where mice must be turned off first and then taken the epithelial tissue.

\section{Conculsion}

Based on research that can be concluded that the lemongrass extract at a concentration of $100 \%$ and $50 \%$ can affect the wound healing process. Buccal wounds of oral mucosa heal faster than labial wound and had an increase in thickness of the epithelium wound healing in the mice. Saliva has an important role in healing process in oral mucosa epithelium. It is expected that further research phytochemical test extracts of lemongrass to find out more about the active compound and further tests about the toxicity, so can be used as a treatment in human oral mucosa.

\section{References}

[1] Sarlina, Razak AR, Tandah MR. Anti-Bacterial Activity Test Preparations Gel Leaf Extract Citronella (Cymbopogon nardus L. Rendle) against Staphylococcus aureus Bacteria Causes Acne. Galenika J. Pharm. 2017; vol 3 (2): 143-9.

[2] Ramadhani N, Sumiwi SA. Anti-inflammatory Activity Suspected Various Plants Derived from flavonoids. FarmakaJ. 2014. Vol 14 (1) (suppl); 111-23.

[3] Nisa VM, Meilawaty Z, Astuti P. Securities Giving Cassava Leaf Extract (Manihotesculenta) Against Wound Healing Process gingiva Rat (Rattus norvegicus). Scientific articles UNEJ Student Research, 2013.

[4] Sugiaman VK. Improved Wound Healing through the Oral Mucosal administration of Aloe Vera (Linn.) SecaraTopikal. JKM 2011; Vol 11: 70-9.

[5] Novyana RM, Susianti. Aloe Vera (Aloe Vera) for Wound Healing. Majority J 2016; Vol 5 (4): 149-53.

[6] Joanna W, Suciati A, Rachmawati M. Improved Buccal Mucosal Epithelium thickness after application Betel Leaf Extract. Maj. Ked. Gi Ind. June 2015; Vol 1 (1): 21-6.

[7] Polito AJ, Proud D. Eptihelial Cells as Regulators of Airway Inflamation. J Allergy ClinImmunol. 2015 Vol 102 (5); 714-7.
[8] Wahyudi IA, Magista M, Angel M. Effectiveness of Use Saliva Compared to Povidone-Iodine $10 \%$ of the cutaneous wound healing in rats Sprague Dawley. 2014. Vol 1 (1).

[9] Hairi M, Dewi N, Khatimah H. Effect of Extract Citronella (Cymbopogon Ciratus) against labial mucosa Long Wound Mice In Clinical. Dentino- J. 2016; Vol 1 (2): 197-202.

[10] MD Nurqadriasti. Test the effectiveness of extracts of lemongrass (Cymbopogon ciratus) to healing cuts on white mice. Dentino- J., 2015.

[11] Nastity GH, Mukhriani, Mulya RH. Wound Healing Effect Test Sayat kecombrang Leaf Ethanol Extract (Etlingera elatior) Gel Preparations In The Form Of Rabbit (Oryctolagus cuniculus). JF Nikken UINAM. 2015; 3 (2): 54.

[12] Sewta CA, Mambo C, Wuisan J. Effects Test Leaf Extract Aloe Vera (Aloe Vera L.) Against Skin Incision Wound Healing Rabbit (Oryctolagus cuniculus). Jurnal e-Biomedicine. 2015; 3 (1): 453.

[13] Puti IR, Melani AM, Hernowo BS, The Role of Topical Leaf Ethanol Extract Noni (Morinda citrifolia L.) In Wound Healing Seen From Imunoekspresi CD34 and collagen in Wistar rats. MKB., 2013; 45 (4): 226.

[14] Fatimatuzzahroh, Firani NK, Kristianto H. Effectiveness Clove Flower Extract (Syzgium aromaticum) Against Total Vein Capillary On Incision Wound Healing Process Phase Proliferation. FKUB Health magazine. 2015; 2 (2): 92.

[15] Meena AK, Ruchika G, Subraya BG, Shobha K, KM Anand, Madhur A et al. A Novel Anti-Oxidant Oil Mouth Wash Lemon grass a Clinical trial. Asian Journal of Experimental Biological Sciences 2011; 2 (3) 842-6.

[16] Francisco V, Figueirinha A, Neves BM, Garcia-Rodriguez C, MC Lopes, Cruz MT et al. Cymbopogon ciratus as a source of new and safe anti-inflammatory drugs: bio-guided assay using lipopolysaccharide-stimulated macrophages. Journal of Ethnopharmacology 2010; 133 (2): 818-27.

[17] Garcia R, Pinto-Ferreira J, Santos T, Costa G, Caramona M, T Batista et al. Evaluation of anti-inflammatory and analgesic activities of Cymbopogon ciratus on in vivo models. European Congress of Pharmacology 2012; 6: 120.

[18] Wahyudi IA, Magista M, Angel M. Effectiveness of Use Saliva Compared to Povidone-Iodine $10 \%$ of the cutaneous wound healing in rats Sprague Dawley. 2014. Vol 1 (1).

[19] Provision of the ointment Winny A. noni leaf extract (Morinda citrifolia) improve the regeneration of injured tissue in males $\mathrm{R}$. norvegicus [thesis]. Denpasar: Udayana University; 2013.

[20] Li J, Chen J, Kirsner R. Pathophysiology of acute wound healing. Clin. Dermatol. 2007; 25: 9-18.

[21] BF Prasetyo, Wientarsih I, Priosoeryanto BP. Activities extract gel banana tree trunk in the process of wound healing in mice. Veterinary Journal. 2010; 11 (2): 70-3.

[22] Jain S. Dermatology. Journal of Ilustrated Study Guide and Comprehensive Board Review. 2012: 2-10.

[23] Soni H, Sighai AK. A recent update of botanicals for wound healing activity. IRJP. 2012; 3: 1-6.

[24] Thakur R, Jain N, Pathak R, and SS Sandhu. Practices in Wound Healing Studies of Plants. Evidence-Based Complementary and Alternative Medicine 2011: 1-15. 
[25] Nayak BS, Sandiford S, and Maxwell A. Evaluation of the Wound-healing Activity of Ethanolic Extract of Morinda citrifolia L. Leaf. Evidence Based Complement Alternative Medicine 2007; 6 (3): 351-6.

[26] Li K, Diao Y, Zhang H, Wang S, Zhang Z, Yu B, et al. Tannin extracts from immature fruits of Terminalia chebula fructus retz. Cutaneous promote wound healing in rats. BMC Complement Med alternat. 2011; 11: 86.

[27] Pastar I, Stojadinovic O, Yin NC, Ramirez H, Aron G, Nusbaum et al. Epithelization in wound healing: A comprehensive review. Wound Healing Society., 2013; 3 (7): 445-64.

[28] Rupina W, Trianto HF, Fitrianingrum I. Effect of $70 \%$ Ethanol Extract Ointment Leaf Re-eptelisasi Karamunting Against Skin Incision Wound Wistar rats. Research article. 2016; 4 (1): 26.

[29] Z. Meilawaty Gum Extracts Test Biduri (Calotropis gigantea) Gingival Fibroblasts Cells Against Wistar rats In Wound Healing. Prodenta Journal., 2013; 1 (2): 71-7. 